\title{
Executive control training does not generalize, even when associated with plastic changes in domain-general prefrontal areas
}

\author{
Marie Simonet $^{\mathrm{a}, *}$, Fabienne Crettaz von Roten ${ }^{\mathrm{a}}$, Lucas Spierer ${ }^{\mathrm{b}, 1}$, Jérôme Barral ${ }^{\mathrm{a}, 1}$ \\ ${ }^{\text {a }}$ Institute of Sport Sciences, Faculty of Social and Political Sciences, University of Lausanne, Lausanne, Switzerland \\ ${ }^{\mathrm{b}}$ Neurology Unit, Medicine Section, Faculty of Science and Medicine, University of Fribourg, Fribourg, Switzerland
}

\section{A R T I C L E I N F O}

\section{Keywords:}

Executive control

Training

Transfer

Event-related potentials

Source localization

\begin{abstract}
A B S T R A C T
How executive function training paradigms can be effectively designed to promote a transfer of the effects of interventions to untrained tasks remains unclear. Here, we tested the hypothesis that training with a complex task involving motor, perceptual and task-set control components would result in more transfer than training with a simple motor control task, because the Complex training would lead to more involvement-and in turn modification —of domain-general executive control networks.

We compared performance and electrophysiological activity before and after 10 days of executive control training with the complex $(n=18)$ versus the simple task $(n=17)$. We further assessed the effect of the two training regimens on untrained executive tasks involving or not one of the trained control components. A passive control group ( $\mathrm{n}=19)$ was used to assess retest effects.

Both training groups improved at the trained task but exhibited different plastic changes within left-lateralized and medial frontal areas at 200-250 ms post-stimulus onset. However, contrary to our hypotheses, they showed equivalent improvement to the passive group to the transfer tasks.

Our collective results reveal that the effect of training with a task involving multiple executive control components is highly specific to the trained task, even when the training modifies the functional networks underlying the trained executive components. Our findings corroborate current evidence that general cognitive enhancement cannot be achieved with training, even when the interventions modify domain-general brain areas.
\end{abstract}

1. Introduction

Executive control (EC) refers to a set of interrelated higher-order cognitive functions involved in the inhibition, switching, or updating of cognitive or motor processes (Barkley, 1996; Miyake et al., 2000). EC enables the dynamic adjustment of behavior to the changing demands of the environment (Aron et al., 2014). While an extensive body of evidence suggests that EC training improves performance at the trained tasks (for a review on inhibitory control training see Spierer et al., 2013), whether and how the effects of EC training transfer to untrained tasks remains unclear.

Current literature suggests that generalization patterns might be improved by increasing the complexity of the task used to train EC. While only limited transfer was observed when inhibitory control was trained with simple Stop-Signal, Stroop, Flanker or Go/NoGo training tasks
(Beauchamp et al., 2016; Enge et al., 2014; Guerrieri et al., 2012; Talanow and Ettinger, 2018; Thorell et al., 2009), larger transfeers were found when EC was trained with difficult or complex tasks combining several closely related executive functions (Maraver et al., 2016; Stevens et al., 2015; Verbruggen et al., 2012). For example, Enge et al. (2014) observed that three weeks of training with Go/NoGo and Stop-signal tasks did not improve performance on a near-transfer Stroop task or on a far-transfer fluid intelligence task (Raven's Advanced Progressive Matrices). Similarly, three-week Stroop task training did not transfer to motor inhibition, task-set shifting, working memory or planning abilities (Talanow and Ettinger, 2018), and three-week stop-signal training did not transfer to an emotion regulation task (Beauchamp et al., 2016). In contrast, Maraver et al. (2016) reported that the effect of six training sessions with difficult inhibition tasks (i.e., tasks with large congruent/incongruent trials ratio, short response time threshold, varying

\footnotetext{
* Corresponding author. Institute of Sport Sciences, Faculty of Social and Political Science University of Lausanne, Quartier UNIL-Centre, Synathlon building, 1015, Lausanne, Switzerland.

E-mail address: marie.simonet@unil.ch (M. Simonet).

1 These two authors contributed equally to this work.
} 
response choices and NoGo stimuli) transferred to untrained close stop-signal, far control strategy and abstract reasoning tasks.

Training with complex tasks could result in larger generalization because such interventions would result in deeper modifications of domain-general executive areas and, in turn, modifications of performance on untrained tasks relying on the same brain network (Buschkuehl et al., 2014; Dahlin et al., 2008; Niendam et al., 2012). In line with this assumption, neuroimaging studies have shown that increasing training task complexity by systematically varying the stimulus-response mapping rules (Benikos et al., 2013; Chavan et al., 2015; Hartmann et al., 2015) or adding supplementary cognitive processes (Scharinger et al., 2015) results in plastic changes within high-order, domain-general executive areas. Corresponding patterns of anatomo-functional modifications of domain-general areas have been observed in populations with expertise in complex executive activities (with elite fencers in Chavan et al., 2017; or fighter pilots in Roberts et al., 2010).

However, most of the studies reviewed above did not directly test whether increasing the complexity of the training tasks truly improves generalization patterns (Benikos et al., 2013; Chavan et al., 2015) or if such effects are indeed mediated by functional changes in domain-general brain areas (e.g., Hartmann et al., 2015; Manuel et al., 2013).

In the present study, we addressed these two questions by testing whether training executive functions with a complex vs a simple control task actually improves generalization patterns and results in larger functional changes in global EC areas. We trained participants for ten days with either a simple Go/NoGo task involving only motor control or with a complex Go/NoGo task in which participants, in addition to inhibiting motor responses, had to dynamically switch between various stimulus-response mapping rules (task-set control components) and to resist the interference from task-irrelevant visual distractors (perceptual control component). A passive control group was used to assess the effects of retest.

The transfer of the effects of training was assessed immediately after the last training session as well as five days later on untrained tasks involving either i) one of the executive components trained in the Simple and/or in the Complex training task (a Go/NoGo task with untrained stimuli, a switching task and an Eriksen flanker task) or ii) an executive component that was not trained but whose underlying brain areas were partly shared with the trained components (a Simon stimulus-response compatibility and a trail making attention/switching task). These two types of transfer tasks respectively allowed for testing the task- and component-specificity of the training regimens (Brass et al., 2003; Chaytor et al., 2006; Miyake and Friedman, 2012; Monsell, 2003; Scharinger et al., 2015).

The transfer effects were statistically assessed with the interaction term of a between-subject factor Training Group (Complex; Simple; Control) and the within-subject factor Time (Pretraining; Posttraining; Retention) calculated for each task separately. Compared to the Simple training group, we predicted that the Complex training group would show i) equivalent direct-transfer: an increase in performance on the Go/ NoGo transfer task because the motor control component was trained in both groups; ii) more near-transfer: a larger increase in tasks measuring one of the cognitive components trained in the Complex task but not the Simple task (Switching, Eriksen flanker); and iii) more far-transfer: a larger increase in the transfer tasks measuring untrained components (Simon, Trail making) because by involving multiple executive components, the Complex training but not the Simple training might have solicited - and thus enhanced-domain-general executive processes also involved in the untrained tasks. Finally, based on previous evidence for long-lasting effects of executive training (months after working memory training in Jaeggi et al., 2011, and Pugin et al., 2014, and a week after Go/NoGo training in Houben et al., 2011), we expected both training groups to maintain any training-induced improvement to the transfer tasks five days after the end of the training. The passive Control group should show a smaller improvement than the two other groups in all tasks because the participants did not perform any cognitive training.

In addition to behavioral investigations, we recorded event-related potentials (ERP) during the training tasks at pre-vs posttraining sessions to examine the spatiotemporal brain dynamics underlying the observed behavioral modifications. We hypothesized that the effect of the complex training, compared to the simple training, would manifest during the N2/P3 components between 200 and $400 \mathrm{~ms}$ post-NoGo onset, when domain-general executive processes typically take place (Kok et al., 2004; Smith et al., 2006; Vuillier et al., 2016). EC training has been shown to result in a reduction of prefrontal activity, a pattern interpreted as a more efficient neuronal processing that would eventually speed up inhibition processes (Chavan et al., 2015; Hartmann et al., 2015). Such effects of training have also been observed at the level of the N2/P3 component when inhibitory control training tasks difficulty was modulated (Benikos et al., 2013). We thus expect to find during the N2/P3 time window a larger initial recruitment, together with a larger decreased activity with training, of the domain-general executive control network, i.e., the right-lateralized ventrolateral and ventromedial prefrontal cortices as well as the anterior cingulate and supplementary motor area with the complex than the simple training (Aron et al., 2003; Berkman et al., 2014; Chavan et al., 2015; Hartmann et al., 2015; Manuel et al., 2013; Rubia et al., 2001; Swick et al., 2008).

\section{Material and methods}

\subsection{Participants}

Fifty-seven right-handed healthy adults were recruited for this study. Our sample size was determined a priori to reach a power of 0.8 to detect, with an alpha of 0.05 and an effect size $f$ of 0.2 (Chavan et al., 2015), with a mixed repeated-measures ANOVA within-between subject interaction including three groups and three measurements. The power analysis indicated that a total sample size of 42 participants was required (calculated by the $\mathrm{G} \times$ Power software, Faul et al., 2007). Based on previous studies with corresponding designs (De Pretto et al., 2017; Hartmann et al., 2015), we added five participants per group to compensate for potential exclusion due to e.g. bad electroencephalogram (EEG) signal, missed training sessions at home or misunderstanding of the instructions.

Written consent was obtained via a consent form completed by all the participants prior to the investigation. The experimental protocol was approved by our local ethics committee (protocol number 462/15).

The participants were randomly assigned to the passive Control group $(n=19)$, the Simple Go/NoGo training group $(n=19)$ or the Complex Go/NoGo training group $(n=19)$. Participants had to fill in a custommade general health questionnaire where they were notably asked about their history of diagnosed neurological and psychiatric diseases. On this basis, we excluded any participant reporting a current or past diagnosed neurological or psychiatric condition. Three participants were excluded from the analyses due to bad EEG signals and one participant was excluded due to missed training sessions at home. The adherence to the sessions performed at home was verified by checking whether each participant actually completed the eight sessions at home and followed the expected procedure (e.g. maximum one training session per day). Fifty-four participants $(26$ female and 28 male; mean age $\pm S D=25.2 \pm 3.5$; all of the participants reported normal or corrected to normal vision and no history of neurological or psychiatric disease) were eventually included in the analyses (Control group $n=19$; Simple Go/NoGo training group $\mathrm{n}=17$; Complex Go/NoGo training group $\mathrm{n}=18$ ).

\subsection{Procedure and tasks}

The participants came to the laboratory at three time points: a pretraining session (Pre), a posttraining session (Post) and a retention session (Ret). At pre- and posttraining, participants completed one session of 
the training task as well as the so-called 'transfer' tasks used to assess the generalization of the effect of training. EEG was recorded during the $\mathrm{Go} /$ NoGo tasks performed during the session at the laboratory (see Fig. 1 for the design of the study). The training duration was eight consecutive days with 50 min of EC training per day. Five days after the posttraining session, the participants came back to the laboratory to complete the retention session, which consisted of the transfer tasks only. The participants were randomly assigned to one of the following training regimens: a Simple Go/NoGo training, a Complex Go/NoGo training and a passive Control group.

Stimulus delivery and response time (RT) recording were monitored by the E-Prime 2.0 software (Psychology Software Tools, Inc., Sharpsburg, PA). A QWERTY keyboard was used as the response tool to record the RT. For the laboratory sessions, participants were seated in a quiet dark room in front of a computer screen. For the training sessions at home, participants were instructed to complete them in a quiet place on a laptop we lent them.

\subsubsection{Training tasks}

2.2.1.1. Simple Go/NoGo training. The simple Go/NoGo training was a classical motor inhibition task. First, a 30-trial block was performed to acclimate the participants to the task. A 'calibration' phase of 23 trials was then completed to estimate the average RT of the participant to Go stimuli (for a similar procedure see De Pretto et al., 2017; Manuel et al., 2010). A RT threshold ( $\mathrm{RTt}=110 \%$ of the mean RT during the calibration phase) was implemented so that a feedback "too late" was displayed on the screen when the participant's RT was above the RTt. A trial started with a white fixation cross displayed centrally on a black background for a duration that randomly varied between 1500 and $2000 \mathrm{~ms}$. Then, a letter surrounded by two hash signs (e.g., $\sharp A \sharp$ ) and chosen among A, E, I, - $\mathrm{K}, \mathrm{L}, \mathrm{N}, \mathrm{O}, \mathrm{R}, \mathrm{T}, \mathrm{U}, \mathrm{X}$ was presented for a time interval ranging from 1500 to $2000 \mathrm{~ms}$ during which participants were instructed to press as fast as possible with the right index finger on the keyboard's spacebar in response to any letter except “ $\sharp \mathrm{X} \sharp$ “ (i.e., the NoGo stimulus). The task included seven blocks of 132 trials each presented randomly with a stimulus probability of 0.7 for the Go and 0.3 for the NoGo stimulus. Every two days the NoGo stimulus changed, so that participants had to inhibit the letter " $\sharp \mathrm{X} \sharp$ " for the first two training sessions, then the letter “ $\sharp \mathrm{A} \sharp$ “, the letter “ $\sharp \mathrm{T} \sharp$ “, the letter “ $\sharp \mathrm{O} \sharp$ “, and finally again the letter " $\sharp$ $\mathrm{X} \#$ “. Inhibitory control performance was assessed by RT to Go stimuli and by the percentage of errors to NoGo stimuli (false alarms, FA).

2.2.1.2. Complex Go/NoGo training. The complex Go/NoGo training was designed to involve working memory, switching and interference suppression components in addition to motor inhibition. Participants performed a 30-trial block to acclimate themselves to the task. A calibration phase of 23 trials was completed as the simple Go/NoGo training to calculate the RTt. Then, three letters (trigrams) chosen among A, E, I, K, $\mathrm{L}, \mathrm{N}, \mathrm{O}, \mathrm{R}, \mathrm{T}, \mathrm{U}, \mathrm{X}$ were presented for a time interval ranging from 1500 to $2000 \mathrm{~ms}$ during which participants were instructed to press as fast as possible with the right index finger on a keyboard's spacebar in response to any trigram except "XXX". However, if a trigram with an " $\mathrm{X}$ " in the middle was presented, such as "TXE" ('goprime'), the instructions for the next trigram changed so that participants were asked to press as fast as possible to any trigram-including " $\mathrm{XXX}$ "- except identical trigrams such as "AAA", "TTT", "EEE", etc. The task included seven blocks of 132 trials each presented randomly with a stimulus probability of 0.1 for $\mathrm{XXX}$, 0.28 for goprime, 0.3 for identical trigram, and 0.32 for all other trigrams combinations. As for the simple Go/NoGo training, every two days the NoGo trigram changed, so that participants had to inhibit the trigram "XXX" for the first two training sessions, then the trigram "AAA", the trigram "TTT", the trigram "OOO", and finally again the trigram "XXX". The goprime and the identical trigrams were adapted accordingly. Inhibitory control performance was assessed by RT to Go stimuli and by the FA rate.

2.2.1.3. Passive control group. The Passive Control group did not perform any task during the eight days of the intervention between the pre- and posttraining sessions. This group however performed Sudokus on a computer during the pre- and posttraining sessions to match their engagement in the pre/post session of the study with the training groups. The participants were asked to complete as many Sudokus as they could during $50 \mathrm{~min}$ on a computer. This game required being able to fill a $9 \times 9$ grid divided into $3 \times 3$ sections with numbers ranging from 1 to 9 whose constraint was that each section, each column and each row had to contain all nine digits.

\subsubsection{Pre- and posttraining transfer tasks}

Participants completed five tasks successively in a random order: a Go/NoGo task, a Simon task, an Eriksen flanker task, a Switching task and a Trail Making task (to avoid confusion, the Go/NoGo task used among the transfer tasks will be referred to as the 'transfer Go/NoGo task'). The transfer tasks were chosen among perceptive-motor tasks previously used in the literature to assess key facets of executive performance. The tasks involved either one of the executive components trained in the simple and/or in the complex training task (the Go/NoGo task with untrained stimuli, the switching task and the Eriksen flanker task) or an executive component that was not trained but whose underlying brain areas were partly shared with the trained components (the Simon task and the Trail making task). This choice of tasks further allowed varying the complexity of the task while keeping constant the type of stimuli and response modes. The tasks were performed at three time points: presession (Pre, day 1), postsession (Post, day 10) and

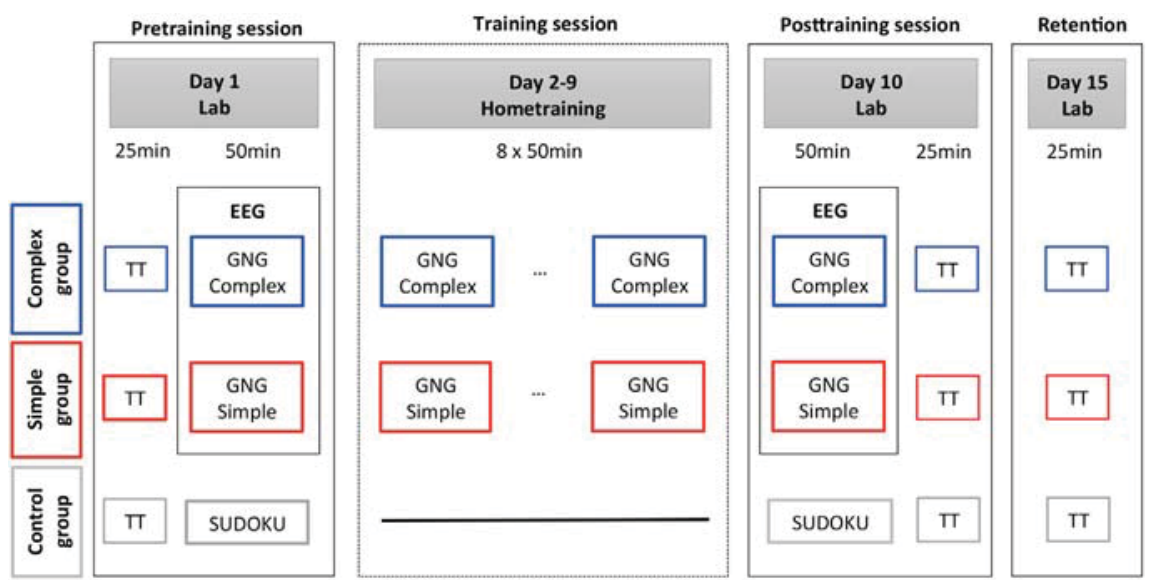

Fig. 1. Experimental Design. TT: transfer tasks; GNG: Go/NoGo task; EEG: electroencephalogram; Lab: laboratory. 
retention (Ret; day 15). Each task lasted approximately 5 min.

2.2.2.1. Transfer Go/NoGo task. In the transfer Go/NoGo task participants had to press as fast as possible with their right index finger on a keyboard's spacebar when the Go stimuli appeared, while withholding responses to NoGo stimuli. A trial started with a preparatory stimulus (empty circle) displayed centrally on a black background for a duration between 800 and $1200 \mathrm{~ms}$. Then, a cross in a circle, i.e., the NoGo stimulus, or a filled circle, i.e., the Go stimulus, appeared for a duration of $200 \mathrm{~ms}$. The next trial started after a time interval of $1000 \mathrm{~ms}$. The task included 2 blocks of 48 trials each, presented in a random order with a stimulus probability of 0.3 for the NoGo stimulus and 0.7 for the Go stimulus. The behavioral performance was assessed by averaging RT to Go stimuli and the FA rate.

2.2.2.2. Eriksen flanker task. The Eriksen flanker task tests the ability to suppress interfering perceptual information from distractors to correctly discriminate the target stimuli (Eriksen and Eriksen, 1974). The trials started with a preparatory stimulus (a cross) displayed centrally on a black background for a duration between 800 and $1200 \mathrm{~ms}$. Then, a stimulus comprising three vertically aligned elements appeared for a duration of $200 \mathrm{~ms}$. The participants were asked to respond as fast as possible with their right index finger on the keyboard's M button when the orientation of the central arrow was facing right ( $\gg$ ) while using their left index finger on the keyboard's Y button when the orientation of the central arrow was facing left $(\ll)$. In the congruent condition, the arrow pointed in the same direction; in the incongruent condition, the central arrow pointed in the opposite direction as the flanker arrow; and in the neutral condition, the central arrow was surrounded by two squares. The stimuli were separated by a time interval of $1000 \mathrm{~ms}$. The task included 2 blocks of 60 trials presented in a random order with a stimulus probability of 0.33 for each condition (i.e., congruent, incongruent, neutral), for a total of 40 congruent, 40 incongruent and 40 neutral trials. The behavioral performance was assessed by subtracting the mean RT of incongruent trials from the mean RT of congruent trials (Eriksen interference index). RT and the percentage of error to the congruent, incongruent and neutral stimuli were also analyzed separately (see the supplementary materials).

2.2.2.3. Switching task. The switching task was divided into three parts (A, B and C ; Monsell, 2003). All trials started with the presentation of a white fixation cross during a duration between 800 and $1200 \mathrm{~ms}$, followed by the display of a number ranging from 1 to 9 except for 5 during $200 \mathrm{~ms}$. Part A and the Part B were considered as the 'pure' condition tasks since only one task was performed (i.e., XXXXX ... and YYYYY ... trials). In Part C, considered as the 'mixed-task', we randomly alternated Part A and Part B instructions (i.e., XYYXYXXY) (Kamijo and Takeda, 2010).

In Part $\mathrm{A}$, the participants were instructed to press as fast as possible with their right index finger on the keyboard's $M$ button when the digit displayed was higher than 5 , while using their left index finger on the keyboard's Y button when the digit displayed was smaller than 5. All of the digits were surrounded by a plain line square. Part A included 1 block of 40 trials presented in a random order with a stimulus probability of 0.5 for each condition (higher or smaller than 5). In Part B, the participants had to press as fast as possible with their right index finger on the keyboard's $M$ button to even numbers and with their left index finger on the keyboard's $Y$ button to uneven numbers. All of the digits were surrounded by a dotted line square. Part B included 1 block of 40 trials presented in a random order with a stimulus probability of 0.5 for each condition (uneven or even). C comprised stimuli from Part A and Part B displayed in a random order. Participants were instructed to use the square surrounding the number to determine which response rule to follow (plain line square for Part A instructions (lower or smaller than 5); dotted line square for Part B instructions (uneven or even number)). This part included 2 blocks of 32 trials each presented in a random order with a stimulus probability of 0.5 for each condition, which represented 32 Part A and 32 Part B trials in total.

The behavioral performance was assessed by subtracting the mean RT of switch trials with the mean RT of no-switch trials during the Part C of the task (i.e., the mixed-task switching cost).

2.2.2.4. Simon task. The Simon task tests the ability to solve a conflict between the side of a stimulus on the screen and the side of the hand used to respond to it (Simon, 1969). A trial started with a preparatory stimulus (a cross) displayed centrally on a black background during a duration that varied from 800 to $1200 \mathrm{~ms}$. Then, a red or a blue square was presented either to the left or the right of the fixation cross for a duration of $200 \mathrm{~ms}$. The participants were instructed to press as fast as possible with their right index finger on the keyboard's $M$ button when a red square was displayed while using their left index finger on the keyboard's $Y$ button when a blue square was displayed, independent of the square's position on the screen. The time interval between the two consecutive trials was $1000 \mathrm{~ms}$. The task included 2 blocks of 40 trials each presented in a random order with a stimulus probability of 0.25 for each condition, i.e., red left (incompatible), red right (compatible), blue left, (compatible) blue right (incompatible), which represented 40 compatible and 40 incompatible trials in total. The behavioral performance was assessed by subtracting the mean RT of incompatible trials by the mean RT of compatible trials (Simon interference index). Additionally, the mean RT and the percentage of error to the compatible and incompatible stimuli were analyzed (see the supplementary materials).

2.2.2.5. Trail making task. The Trail making task tests visuo-spatial and flexibility skills (Salthouse, 2011). The task was divided into two parts, i.e., Part A and Part B, always performed in this order. In Part A, the participants were instructed to connect as fast as possible 25 circles containing 25 numbers, ranging from 1 to 25 , in a numerically ascending order. Part B included 25 circles comprising a mix of numbers (from 1 to 13) and letters (from A to L) that the participants were asked to connect as fast as possible in an alternatively numerically and alphabetically ascending order. The behavioral performance was assessed by dividing the time spent to perform Part B by the time spent to perform Part A in seconds (secTMTB / secTMTA ratio).

\subsection{Behavioral analyses}

Behavioral statistical analyses were performed using the Statistical Package for the Social Sciences 24 (SPSS Inc., Chicago, Illinois, USA) for the Go/NoGo training analyses, the Statistica version 13.3 (TIBCO Software Inc. (2017), Palo Alto CA, USA, http://statistica.io) for the transfer tasks analyses and JASP software (Version 0.8.3.1, https://jasp-stats.org) for the Bayesian inferences. For all of the tasks, RT was subject to a procedure excluding trials $<100 \mathrm{~ms}$ and $>2$ standard deviations to individual's mean RT.

\subsubsection{Go/NoGo training tasks}

The effects of training were assessed with repeated-measures ANOVAs with Groups (Complex vs Simple) as the between-subject factor and Time (Pre $v s$ Post) as the within-subject factor (see Fig. 1 for the design of the study). All of the variables were controlled for normality using the Shapiro-Wilk test and for the structure of variance-covariance using the Mauchly's sphericity test. P-values were corrected either with Greenhouse and Geisser or Huynh and Feldt corrections when Mauchly's test was significant. Bonferroni correction was used to adjust for multiple comparisons. Effect sizes were computed using eta-squared. The statistical significance was set at $\mathrm{p}<.05$.

\subsubsection{Transfer tasks}

2.3.2.1. Behavioral outcome. Boxplot diagrams were used to identify 
outliers for each dependent variable. The values 1.5 times the interquartile range above the third quartile or below the first quartile were considered as outliers (Wade, 2005). Two participants in the Control group with $10 \%$ of all of the dependent variables being outliers were excluded from the data set. Four other participants (one in the Complex group, one in the Simple group and two in the Control group) presented one or two outlying values. We replaced each value by the group's mean of the dependent variable. The data set for the transfer tasks was composed of 18 participants in the Complex group, 17 participants in the Simple group and 17 participants in the Control group.

Shapiro-Wilk tests with a significance threshold set at $\mathrm{p}<.05$ were used to evaluate the normality of each dependent variable. Levene's tests indicated no violation of homogeneity of variance among groups for the majority of the variables.

2.3.2.2. Outcome-neutral analyses. A one-way ANOVA with the factor Group (Complex; Simple; Control) was computed for each dependent variable for the pretraining session to check whether the three groups did not differ at baseline.

2.3.2.3. Effect of training and retention analyses. Group (Complex; Simple; Control) x Time (Pre; Post; Ret) mixed repeated-measures ANOVAs were computed for each behavioral outcome separately to analyze the training and the retention effects in all of the tasks. We used nonparametric Kruskal-Wallis ANOVAs for evaluating the Group effect for each Time condition and Friedman ANOVAs for the training and retention effects within each Group when the assumptions for parametric tests were not met.

Effect sizes were computed using partial eta-squared for parametric ANOVA, eta-squared for Kruskal-Wallis ANOVA, and Kendall's coefficient of concordance (W) for the Friedman ANOVA. Kendall's W looks at agreement between participants and gives a value that ranges between 0 and 1 . Kendall's $\mathrm{W}$ uses the Cohen's interpretation guidelines of $0.1=$ small effect, $0.3=$ moderate effect and above $0.5=$ large effect.

Due to the high number of statistical analyses performed and because these statistical terms tested our primary hypothesis, only the main tasks' measures, i.e., Go/NoGo RT and FA, Simon interference index, Eriksen interference index, SwitchCost, and TMT B/A ratio, are reported in the results section "3.1.2 Transfer tasks: training effects and retention". For the statistical details on the subcomponents of the transfer tasks, please refer to the supplementary materials.

To complement the results of the frequentist approach, we conducted a Group (Complex; Simple; Control) by Time (Pre; Post; Ret) mixed ANOVAs model using Bayesian inference (for a similar approach with working memory training see Guye and von Bastian, 2017) for behavioral outcomes that showed nonsignificant Group $\times$ Time interactions with the frequentist approach (see the results section "3.1.2 Transfer tasks: training effects and retention"), i.e., Eriksen interference index, SwitchCost and the TMT B/A ratio with the default priors ( $\mathrm{r}$ scale fixed effects $=0.5 ; \mathrm{r}$ scale random effects $=1$ ). The Bayes factor $\mathrm{BF}_{10}$ is a ratio of probability indicating how many times the alternative hypothesis (i.e., Group $\times$ Time interaction occurs) is more likely to occur than the null hypothesis (i.e., no interaction). $\mathrm{A} \mathrm{BF}_{10}$ score superior to $1 / 3$ indicates an anecdotal evidence for the null hypothesis, while a $\mathrm{BF}_{10}$ score inferior to $1 / 3$ or $1 / 10$ represents, respectively, moderate or strong evidence for the null hypothesis (Lee and Wagenmakers, 2014).

\subsection{Recording and data pre-processing}

EEG data were acquired at a sampling rate of $2048 \mathrm{~Hz}$ with a 64-channel Biosemi Active two amplifier system (Biosemi, Amsterdam, Netherlands) and processed using the Brain Vision Analyzer 2 (Brain product, Munich, Germany, 2.1 Version), the Cartool Software elaborated by Denis Brunet (brainmapping.unige.ch/cartool) and the STEN software developed by Jean-François Knebel and Michael Notter (http://doi.org/10.5281/zenodo.1164038).

After a $512 \mathrm{~Hz}$ down sampling and filtering $(0.31-40 \mathrm{~Hz}$ bandpass, $50 \mathrm{~Hz}$ Notch and DC removed), we performed an independent component analysis to remove eye blink artefacts. Artefacted electrodes were interpolated using 3D splines (Perrin et al., 1987) leading to an average of $4.2 \%$ of interpolated electrodes. The data were recomputed against the average reference. The epochs were then segmented and averaged from $100 \mathrm{~ms}$ pre-stimulus to $500 \mathrm{~ms}$ post-stimulus onset, separately for Go and NoGo stimuli, for the day 1 (Pre) and the day 10 (Post). Only successful Go and NoGo epochs respecting the $\pm 80 \mu \mathrm{V}$ artifact rejection criterion were considered in the event-related potentials (ERPs). An average of epochs $( \pm \mathrm{SD})$ for the Complex group Go Pre $49.5 \pm 5$ (mean: $2.4 \%$ rejection); Go Post $49.5 \pm 4.5$ (mean: $3 \%$ rejection); NoGo Pre $68.3 \pm 6$ (mean: $2.8 \%$ rejection); NoGo Post $65 \pm 10.5$ (mean: $2.8 \%$ rejection) and for the Simple group Go Pre $161.9 \pm 13.8$ (mean: $1.6 \%$ rejection); Go Post $160.6 \pm 12.7$ (mean: $3.2 \%$ rejection); NoGo Pre $83.3 \pm 8.4$ (mean: $2 \%$ rejection); NoGo Post $82 \pm 6.4$ (mean: $2.2 \%$ rejection) was eventually included in the statistical analyses.

\subsection{Analyses}

\subsubsection{Event-related potentials}

As for the behavioral analyses, we focused only on the Group $\times$ Time interaction term because it captured the differential effect of training, which was the question of our study. The main effect of Time would indeed reveal a retest effect (e.g., mere exposure or familiarization with the tasks), and the main effect of Group was controlled by the randomization and potentially confounded by the interaction with the different training regimens.

We first computed an analysis in the sensor space using a Group (Complex; Simple) x Time (Pre; Post) x Stimulus (Go; NoGo) repeatedmeasures ANOVA at each time-frame of the ERP and for each electrode to identify whether and when the interaction occurred. To control for multiple tests, we considered only Group $\mathrm{x}$ Time $\times$ Stimulus interaction effects with a p-value $<.05$ and for at least 11 continuous time frames on at least $10 \%$ of the electrodes (Guthrie and Buchwald, 1991). The source estimations were then conducted over the period of interest identified by the ERP analyses.

\subsubsection{Electrical source estimations}

Electrical source estimations were performed using a local autoregressive average (LAURA) distributed linear inverse solution (Grave-de Peralta et al., 2001; Grave-de Peralta et al., 2004). The solution space (i.e., the lead field matrix) was calculated on a realistic head model that included 3005 nodes, selected from a $6 \mathrm{~mm} \times 6 \mathrm{~mm}$ x $6 \mathrm{~mm}$ grid of voxels equally distributed within the gray matter of the average brain of the Montreal Neurological Institute (MNI). For the analyses in the source space, ERPs were first averaged over the period of interest identified during the time-frame (TF) wise ERP analysis for each subject and each condition separately (De Pretto et al., 2017; Sallard et al., 2018). Then, the source of the resulting $1 \mathrm{TF}$ ERPs were estimated and the current densities at each solution point submitted to the same Group $\mathrm{x}$ Time $\mathrm{x}$ Stimulus statistical design as for the ERPs analyses. To control for multiple tests, we considered only clusters showing a p-value $<.05$ and composed of at least 15 contiguous nodes. Bonferroni correction was used to adjust the follow-up tests for multiple comparisons.

\section{Results}

\subsection{Behavior}

\subsubsection{Go/NoGo training: Group (Complex; Simple) x Time (Pre; Post)}

3.1.1.1. Response time. There was a main effect of Group for the RT, driven by generally longer RT in the Complex group than in the Simple 
group $\left(\mathrm{F}_{1,33}=4.31 ; \mathrm{p}=.046 ; \eta^{2}=0.115\right)$. There was a main effect of Time driven by a decrease in RT through the training for both groups $\left(F_{1,33}=145.04 ; p<.0001 ; \eta^{2}=0.815\right)$. There was a significant Group (Complex; Simple) $x$ Time (Pre; Post) interaction $\left(\mathrm{F}_{1,33}=29.01\right.$; $\left.\mathrm{p}<.0001 ; \eta^{2}=0.469\right)$. The post hoc tests indicated that the interaction was driven by slower RT in the Complex group than in the Simple group at pretraining but not at posttraining (Table 1 \& Fig. 2 for the behavioral performance during the Go/NoGo training).

3.1.1.2. False alarm. There was no main effect of Group for the FA rate $\left(\mathrm{F}_{1,33}=2.2 ; \mathrm{p}=.148\right)$. There was a main effect of Time driven by an increase in the FA rate throughout the training for both groups $\left(\mathrm{F}_{1,33}=62.11 ; \mathrm{p}<.0001 ; \eta^{2}=0.653\right)$. There was no Group (Complex; Simple) $\mathrm{x}$ Time (Pre; Post) interaction $\left(\mathrm{F}_{1,33}=1.17 ; \mathrm{p}=.287\right.$ ) (Table $1 \&$ Fig. 2 for the behavioral performance during the Go/NoGo training).

3.1.1.3. Correlation $\triangle R T-\triangle F A$. To test for the relationship between the RT decrease and FA increase with training (i.e., for potential speedaccuracy trade-offs, Heitz, 2014), we computed Pearson's correlation coefficients between the delta of the two dependent variables for each group separately. The analyses showed no relationship between $\Delta \mathrm{RT}$ and $\Delta$ FA (Pre subtracted by Post values) for the Complex (r $(16)=-0.44$; $\mathrm{p}=.065)$ or the Simple ( $\mathrm{r}(15)=-0.31 ; \mathrm{p}=.226$ ) groups.

\subsubsection{Transfer tasks: training effects and retention}

Only the main tasks' measures, i.e., Go/NoGo RT and FA, Simon interference index, Eriksen interference index, SwitchCost, and TMT B/A ratio, are reported in this section (Fig. 3). For all tasks' measures, please see Table 2. For the statistical details on the subcomponents of the tasks, please refer to the supplementary materials.

3.1.2.1. Outcome-neutral analyses. There was no effect of Group (all $p>.05)$ for any of the transfer tasks' measures, providing no evidence that the three groups differed at the pretraining session.

3.1.2.2. Go/NoGo transfer task: response time \& false alarm rate.Response time: there was no main effect of Group for the RT $\left(\mathrm{F}_{2,49}=1.30 ; \mathrm{p}=.28\right)$, but there was a main effect of Time $\left(\mathrm{F}_{2,98}=41.5\right.$; $\left.\mathrm{p}=.000 ; \eta_{\mathrm{p}}^{2}=0.45\right)$ and a Group $\times$ Time interaction $\left(\mathrm{F}_{4,98}=2.66\right.$; $\left.\mathrm{p}=.037 ; \eta_{\mathrm{p}}^{2}=0.09\right)$. The post hoc tests demonstrated that the RTs at Post $(265 \pm 26 \mathrm{~ms})$ and at retention (Ret) $(260 \pm 22 \mathrm{~ms})$ were lower than those at Pre $(292 \pm 27 \mathrm{~ms})$ in the Complex group (all $\mathrm{p}<.0001)$ and in the Simple group (Pre: $291 \pm 28 \mathrm{~ms}$; Post: $272 \pm 22 \mathrm{~ms}$; Ret: $266 \pm 18 \mathrm{~ms}$ ) (all p <.003). There was no decrease in RT in the passive Control group.

False alarm: there was a Group effect at Ret $(\mathrm{H}(2)=7.42 ; \mathrm{p}=.024$; $\left.\eta^{2}=0.11\right)$ but not at Pre $(\mathrm{p}=.444)$ and Post $(\mathrm{p}=.051)$. Post hoc tests revealed a significant difference $(\mathrm{p}=.022)$ between the Complex $(15.7 \%)$ and the Control groups $(7.0 \%)$ but not between the Simple (9.2\%) and the Control groups or between the Complex and the Simple groups. There was a Time effect in the Complex group $\left(\chi^{2}(\mathrm{~N}=18\right.$, $\mathrm{df}=2)=19.01 ; \mathrm{p}<.001$; Kendalls' $\mathrm{W}=0.53$ ) but not in the two other groups $(\mathrm{p}=.321$ and $\mathrm{p}=.616$ respectively for the Simple and the Control groups). This effect was driven by higher FA rate at Post (19.4\%) and Ret (15.7\%) when compared to Pre (6.3\%).

3.1.2.3. Simon task: Simon interference index. There was no main effect of Group and no main effect of Time (respectively, $\mathrm{F}_{2,49}=2.04 ; \mathrm{p}=.14$ and $\mathrm{F}_{2,98}=1.72 ; \mathrm{p}=.18$ ). There was a significant Group $\times$ Time interaction $\left(\mathrm{F}_{4,98}=2.49 ; \mathrm{p}=.047 ; \eta_{\mathrm{p}}^{2}=0.09\right)$. While the interaction seemed to be driven by a difference between the Control group and the training groups at retention, none of the Bonferroni post hoc tests reached significance.

3.1.2.4. Eriksen flanker task: Eriksen interference index. There was no main effect of Group for the interference index $\left(F_{2,49}=0.64 ; \mathrm{p}=.53\right)$. There was a main effect of Time $\left(\mathrm{F}_{2,98}=4.14 ; \mathrm{p}=.018 ; \eta_{\mathrm{p}}^{2}=0.08\right)$, with a significant decrease only between Post and Ret $(\mathrm{p}=.029)$. There was no Group $\times$ Time interaction $\left(\mathrm{F}_{4,98}=0.33 ; \mathrm{p}=.85\right)$. The Bayesian analysis showed a $\mathrm{BF}_{10}$ of 0.07 for the interference index Group (Complex; Simple; Control) x Time (Pre; Post; Ret) interaction, indicating strong evidence for the null hypothesis (i.e., no interaction).

3.1.2.5. Switching task: SwitchCost. There was no main effect of Group for the switch cost values (SwitchCost A: $F_{2,49}=0.08 ; p=.92$; SwitchCost $\mathrm{B}: \mathrm{F}_{2,49}=0.17 ; \mathrm{p}=.83$ ). There was a main effect of Time in the SwitchCost A $\left(\mathrm{F}_{2,98}=5.64 ; \mathrm{p}=.005 ; \eta_{\mathrm{p}}^{2}=0.10\right)$ and the SwitchCost B $\left(\mathrm{F}_{2,98}=24.76 ; \mathrm{p}<.001 ; \eta_{\mathrm{p}}^{2}=0.34\right)$. In the two conditions, the switch cost values decreased from Pre to Ret with differences between Pre and Ret $(\mathrm{p}=.004)$ for the SwitchCost A and between Pre and Post $(\mathrm{p}<.0001)$

Table 1

Behavioral data and statistical analyses of the performance at the first and the last Go/NoGo training session. RT $=$ response time; FA $=$ false alarm; Pre $=$ day 1 ; Post $=$ day 10 . Means, standard deviations, $\mathrm{p}$-values and effect sizes are displayed.

\begin{tabular}{|c|c|c|c|c|c|c|c|}
\hline \multirow[b]{2}{*}{ Mean \pm SD } & \multicolumn{2}{|c|}{ Complex } & \multicolumn{2}{|c|}{ Simple } & \multirow[b]{2}{*}{ Group effect } & \multirow[b]{2}{*}{ Time effect } & \multirow[b]{2}{*}{ Group $\times$ Time interaction } \\
\hline & Pre & Post & Pre & Post & & & \\
\hline \multirow[t]{2}{*}{ RT (ms) } & 441.4 & 345.3 & 390 & 353.3 & $\mathrm{p}=.046$ & $\mathrm{p}<.0001$ & $\mathrm{p}<.0001$ \\
\hline & \pm 45.8 & \pm 23.4 & \pm 36.7 & \pm 29.5 & $\eta^{2}=.115$ & $\eta^{2}=.815$ & $\eta^{2}=.469$ \\
\hline \multirow[t]{2}{*}{ FA (\%) } & 12.7 & 27.7 & 10.6 & 21.9 & $\mathrm{p}=.148$ & $\mathrm{p}<.0001$ & $\mathrm{p}=.287$ \\
\hline & \pm 5.7 & \pm 12.5 & \pm 6.7 & \pm 10.4 & & $\eta^{2}=.653$ & \\
\hline
\end{tabular}
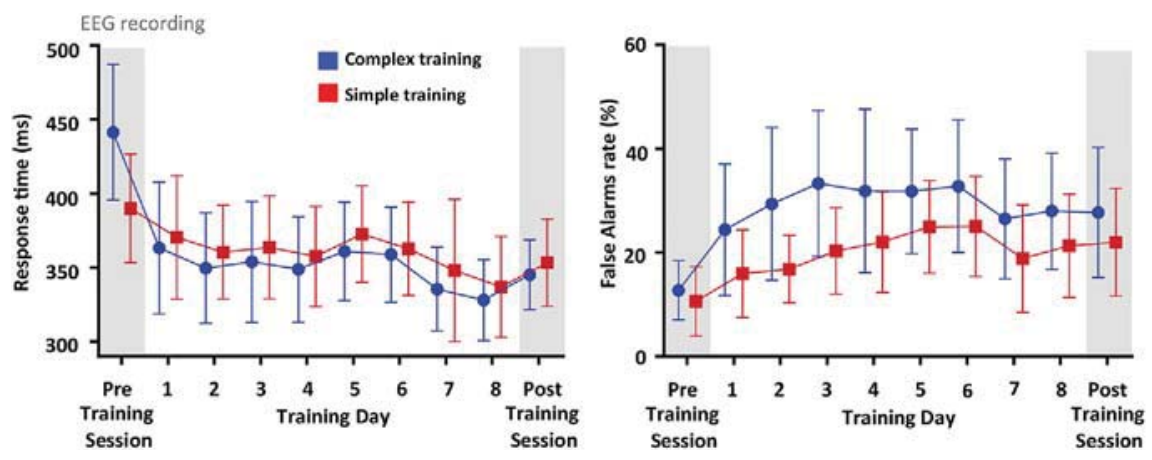

Fig. 2. Behavioral performance during the Go/NoGo training. Means and standard deviations are represented. 

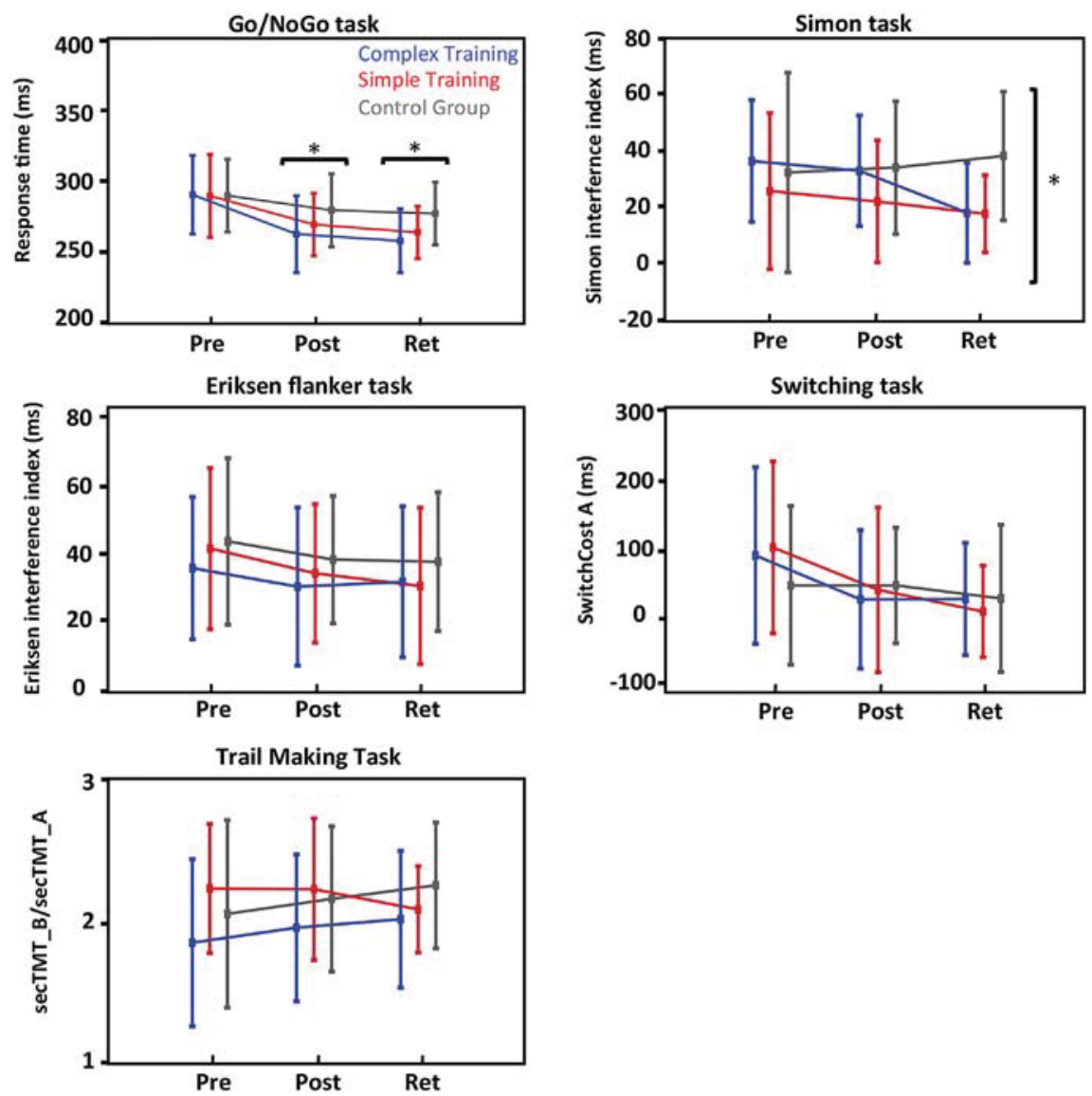

Fig. 3. Behavioral performance in the transfer tasks: Pre-, post- and retention sessions. Means and standard deviations are represented. * $=$ significant Group $\times$ Time interaction.

and Pre and Ret $(\mathrm{p}<.001)$ for the SwitchCost B. There was no Group $\times$ Time interaction (SwitchCost A: $\mathrm{F}_{4,98}=1.01 ; \mathrm{p}=.40$; SwitchCost $\mathrm{B}: \mathrm{F}_{4,98}=0.84 ; \mathrm{p}=.49$ ). Bayesian analysis showed a $\mathrm{BF}_{10}$ of $0.2(\mathrm{~A})$ and 0.13 (B) for the SwitchCost Group (Complex; Simple; Control) x Time (Pre; Post: Ret) interaction, indicating moderate evidence for the null hypothesis (i.e., no interaction).

3.1.2.6. Trail making task: $B / A$ ratio. There was no main effect of Group and Time factors or for the Group $\times$ Time interaction (respectively, $\left.\mathrm{F}_{2,49}=2.05 ; \mathrm{p}=.14 ; \mathrm{F}_{2,98}=0.42 ; \mathrm{p}=.65 ; \mathrm{F}_{4,98}=0.99 ; \mathrm{p}=.41\right)$. The Bayesian analysis showed a $\mathrm{BF}_{10}$ of 0.14 for the TMT ratio Group (Complex; Simple; Control) x Time (Pre; Post: Ret) interaction, indicating moderate evidence for the null hypothesis (i.e., no interaction).

\subsection{Electrical neuroimaging results}

3.2.1. Event-related potentials and source estimations analyses: Group (Complex; Simple) x Time (Pre; Post) x Stimulus (Go; NoGo) design

The group-averaged ERP of an exemplar waveforms (Fz) is displayed in Fig. 4A. There was a sustained Group $x$ Time $\times$ Stimulus interaction ( $\mathrm{p}<.05 ;>10 \%$ electrodes) from 200 to $250 \mathrm{~ms}$ over frontal and occipital electrodes (Fig. 4B). Within this time window the Fz exemplar waveforms of the Complex group presented higher amplitude in the Go and mainly in the NoGo stimulus compared to the other conditions at Pre (Fig. 4A). The statistical analyses of the source estimations over the $200-250 \mathrm{~ms}$ period of interest (POI) (Fig. 4C) revealed a significant Group $\mathrm{x}$ Time $\times$ Stimulus interaction in left-lateralized and medial frontal regions separated in two distinct clusters: one including the left insula and the left inferior frontal gyrus (cluster 1); one including the superior frontal gyrus, the medial frontal gyrus and the anterior cingulate (cluster 2). We then split the two stimuli for the further ANOVAs analyses and we performed a Group x Time mixed ANOVA for NoGo and Go separately. We found a Group $\times$ Time interaction in the NoGo condition for the two clusters ( $\mathrm{p}=.013$ for the cluster $2 ; \mathrm{p}=.012$ for the cluster 1 ). The posthoc analyses indicated that the interaction was driven by higher activity to the NoGo stimulus for the Complex group within both clusters (cluster 2: $\mathrm{p}=.011$; cluster $1 \mathrm{p}=.026$ ) at Pre. In the cluster 2 , a decrease to the NoGo was found between Pre and Post for the Complex group $(\mathrm{p}=.026)$. The group-averaged density values for each cluster are presented in the bar graphs of Fig. 4C.

\section{Discussion}

We examined the behavioral and functional effects of a 10-day executive control training with a complex versus a simple Go/NoGo task.

Practicing the training tasks resulted in an overall performance improvement on the training task in both training groups. Electrical neuroimaging analyses of the ERP revealed that the behavioral improvement was associated with different effects of the Complex and Simple training during inhibition-related activity in the left-lateral and medial frontal areas at $200-250 \mathrm{~ms}$ post-stimulus onset.

There was equivalent improvement to the Flanker and the Switching tasks for the Complex, Simple and passive Control groups. Yet, compared to the passive training group, the two active training groups showed a larger improvement for the Simon task at the retention session. Finally, the Simple group but not the Complex or the Control group showed an improvement for the Go/NoGo task with untrained stimuli. 
Alarm; Err: error; COMP: Compatible condition; INCOMP; Incompatible condition; CONG: Congruent condition; INCONG: Incongruent condition; NEUTR: Neutral condition; ns = non-significant; p = p-values.

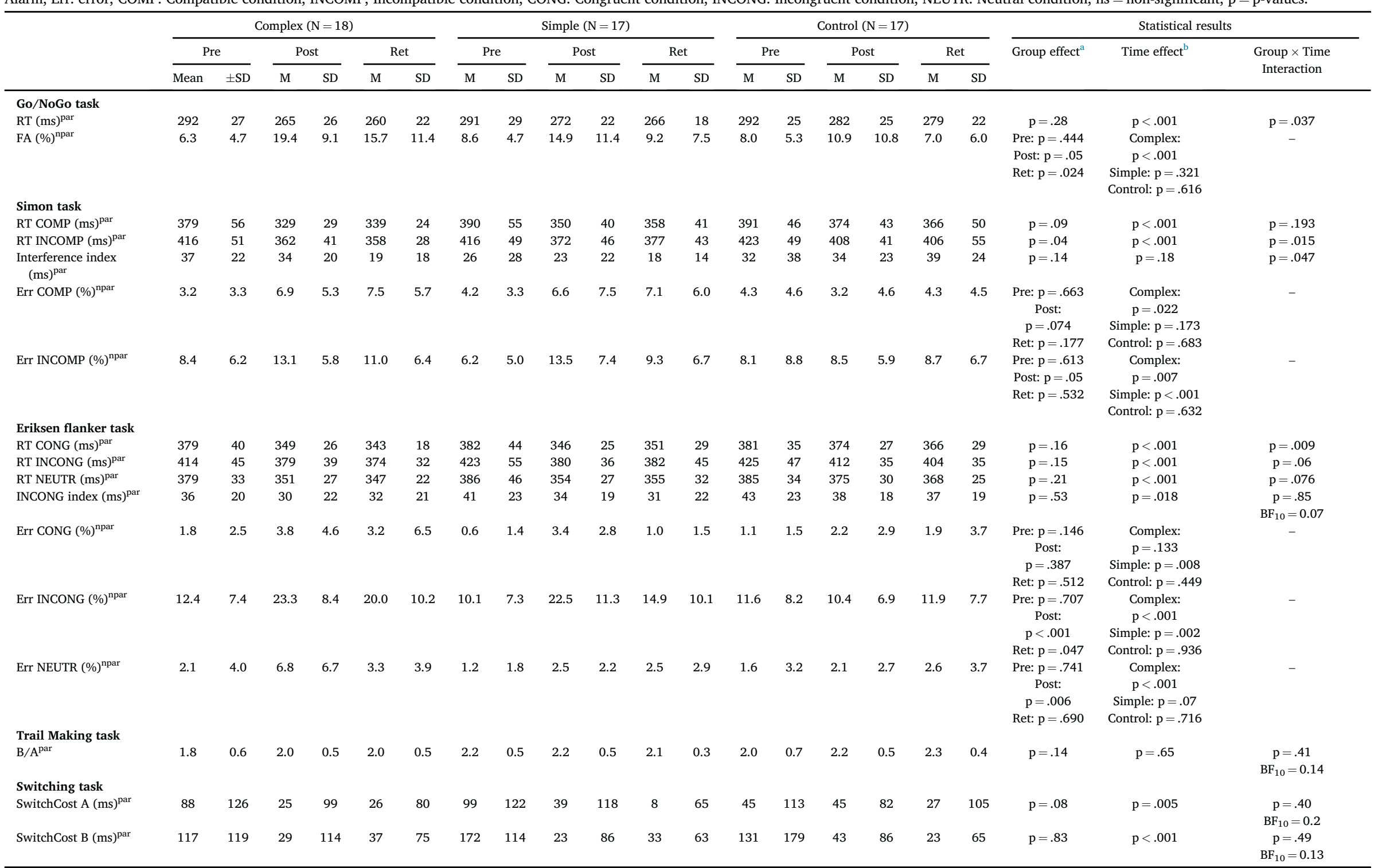

par this dependent variable was analyzed using parametric tests.

${ }^{n p a r}$ this dependent variable was analyzed using non-parametric tests.

a Kuskall-Wallis ANOVA for group effect.
b Friedman ANOVA for Time effect. 


\subsection{The training improved performance at the trained task}

Behaviorally, both groups showed a decrease in RT with training to the training task. However, the improvement was larger in the Complex than in the Simple group. This Time by Group interaction was driven by larger RT in the Complex group than in the Simple group at pre- but not posttraining. Although the initially slower RT in the Complex training task confirms that it was more difficult (see, e.g., Gajewski and Falkenstein, 2013; Maguire et al., 2009 for other examples of positive slowdown-complexity relationships in Go/NoGo tasks), ten days of training was sufficient for the participants in the Complex group to reach the level of those practicing the simple Go/NoGo task. Such convergence in the performance between the two groups with training likely reflects the ability of our healthy young adult participants to quickly automatize even complex, multicomponent executive tasks (Kray and Fehér, 2017; Maraver et al., 2016).

Importantly, the decrease in RT with training was associated with a general increase in the FA rate, suggesting the presence of a speedaccuracy trade-off. However, the absence of a correlation between the decrease in RT and the increase in the FA rate during the training suggests that such phenomena cannot fully account for the observed pattern of result. Rather, given that the decrease in RT was of larger amplitude than the increase in FA, we interpret our pattern of behavioral results as an improvement in the speed of inhibitory control with training. Race models indeed indicate that during NoGo trials the 'race' between execution and inhibition determines the accuracy; thus, an increase in the speed of execution process with a low increase in the rate of commission errors necessarily indicates that the speed of inhibition also increases (Verbruggen and Logan, 2015; Logan et al., 2014; see (Benikos et al., 2013; Chavan et al., 2015; Chavan et al., 2017; Hartmann et al., 2015; Manuel et al., 2010 for similar behavioral patterns with Go/NoGo training).

4.2. Training tasks complexity modulates how early conflict detection and executive control functional processing phases are modified by the training

The analyses of the ERP during the training tasks revealed a Group (Complex; Simple) x Time (Pre; Post) x Stimulus (Go; NoGo) interaction 200-250 ms post-stimulus onset. We localized the sources of this effect within a fronto-medial network including the superior and medial frontal gyrus (SFG; MFG) and the anterior cingulate (AC), and a fronto-lateral network including the left insula and the left inferior frontal gyrus (IFG). The interaction was driven by a reduction in training of the initially stronger response to the NoGo stimuli in the Complex than in the Simple group within the fronto-lateral and fronto-medial areas. Critically, these results confirm that increasing the training task complexity increases training-induced plastic changes taking place during global, domaingeneral processing phases (Hartmann et al., 2015; Chavan et al., 2015).

The time-period of the ERP interaction corresponds to the beginning of the N2 components, a period typically associated with the detection and resolution of response conflict (Donkers and van Boxtel, 2004; Enriquez-Geppert et al., 2010; Gajewski and Falkenstein, 2013; Nieuwenhuis et al., 2003; Schmajuk et al., 2006), and the initiation of the inhibitory control process (Bokura et al., 2001; De Pretto et al., 2017; Falkenstein et al., 1999; Millner et al., 2012). Increases in the N2 component amplitude have for instance been observed when individuals had to suppress interference from task-irrelevant information, such as in Eriksen flanker tasks (Danielmeier et al., 2009; Fong et al., 2018; Larson et al., 2014; Yeung and Cohen, 2006). Importantly, the localization of our effect supports this interpretation: medial frontal areas were indeed previously involved in the prevention of future conflicts, the suppression of inappropriate actions and information interference (Bokura et al., 2001; Kropotov and Ponomarev, 2009; Nieuwenhuis et al., 2003; Yeung and Cohen, 2006). The SFG was associated with the monitoring of information within the working memory network (du Boisgueheneuc et al., 2006), and left lateral prefrontal areas in suppressing ongoing action and attentional switching (Konishi et al., 1998; Rubia et al., 2001; Swick et al., 2008), especially in situations of high task difficulty (Colcombe et al., 2005; Hirose et al., 2012; Langenecker and Nielson, 2003; Nielson et al., 2002).

Together with the behavioral result for slower performance in the complex task, the larger involvement of these areas in the Complex task than in the Simple task at the beginning of the training ensures that our choices of tasks parameters had the expected effects: compared to the simple task, the complex task loaded more strongly on the conflict processing and inhibitory control because participants had to inhibit the flankers and the previous stimulus-response mapping rules after switching.

Second, the direction of our effect (decrease in activity in the Complex group but not the Simple group with training), suggests that the practice of the task reduced the need for additional executive neural resources to solve the complex task. This result is consistent with the behavioral results showing a convergence in the performance between the two groups with training, and corroborates previous evidence for reduction of prefrontal inhibition-related activity with inhibitory control training (Chavan et al., 2015; Hartmann et al., 2015; Manuel et al., 2013). As already presented in the previous literature, a decrease in functional activity putatively follows from neural sharpening mechanisms consisting of the exclusion of task-unspecific activity to increase the efficiency of the inhibition process. Our finding could likewise be accounted for by an automatization of the inhibition process in the Complex but not Simple training group: because of the very simple rules of the simple task, it would have been already automatized at the end of the $50 \mathrm{~min}$ practice of the pretraining session (Chavan et al., 2015; Hartmann et al., 2015; Manuel et al., 2013). Such a decrease in prefrontal involvement with executive training has been regularly observed in studies on planning (Beauchamp et al., 2003), working memory (Hempel et al., 2004) or switching (Jimura et al., 2014) tasks. For example, diminished N2 amplitude along with a reduced RT interference effect have been associated with improved interference resolution mechanisms, assuming a shift from controlled to automatic response modes (Millner et al., 2012).

Finally, the spatiotemporal loci showing the interaction corresponded to domain-general areas, late-latency medial and lateral areas activity have been repeatedly pointed out for EC across tasks ranging from switching tasks (Menon and Uddin, 2010), n-back tasks (Buschkuehl et al., 2014) to flanker tasks (Berron et al., 2015). This pattern corroborates previous findings that training with a complex task results in larger modification of global, domain-general areas than training with simple tasks.

\subsection{The complexity of the training task did not influence generalization patterns}

Regarding the transfer effects, we hypothesized that training with a complex Go/NoGo task would result in a larger transfer of the training effects to untrained tasks because it would more strongly solicit-and thus modify-domain-general executive control processes.

Our result did not confirm this hypothesis. The Complex training resulted in equivalent improvement of the transfer tasks with the two other groups on the untrained Eriksen flanker and the Switching tasks. This finding indicates a high selectivity of the effect of training on the trained task; mere retest effects accounted for most of the observed change in performance between the pre- and posttraining session. Just after the training period, the absence of transfer was indeed not only observed for tasks sharing only distant cognitive components with the trained tasks (i.e., the Simon and Trail making tasks) but also for tasks whose key cognitive components were directly trained in the Complex group but not in the Simple training group (the Eriksen flanker and the Switching task). As a positive control for this interpretation, the Simple group, which was only trained with a task identical to the Go/NoGo transfer task (except the stimuli), was only showing improvement at that task. 


\section{A. Exemplar group-averaged ERP waveforms}
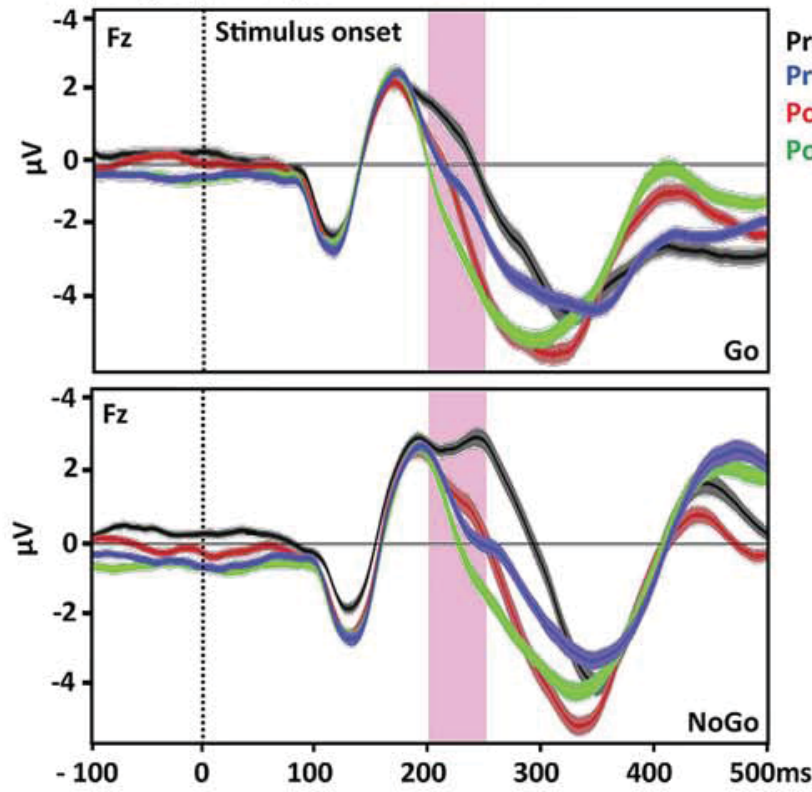

B. ERP Waveforms: Group $x$ Session $x$ Stimulus interaction

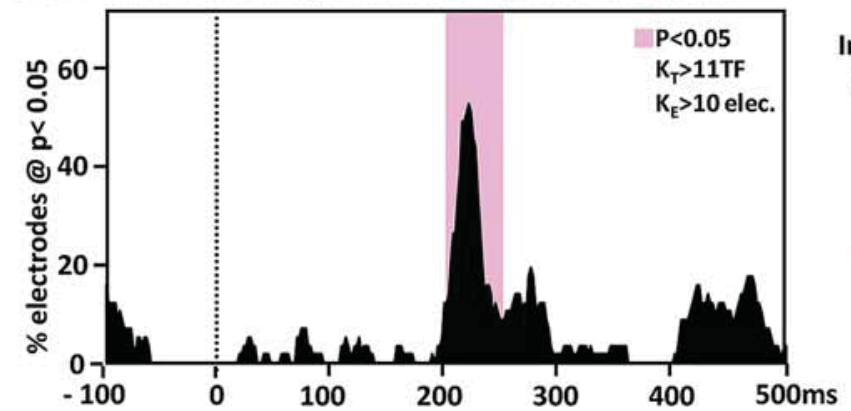

\section{Source Estimations: Group x Session x Stimulus interaction (200-250ms)}

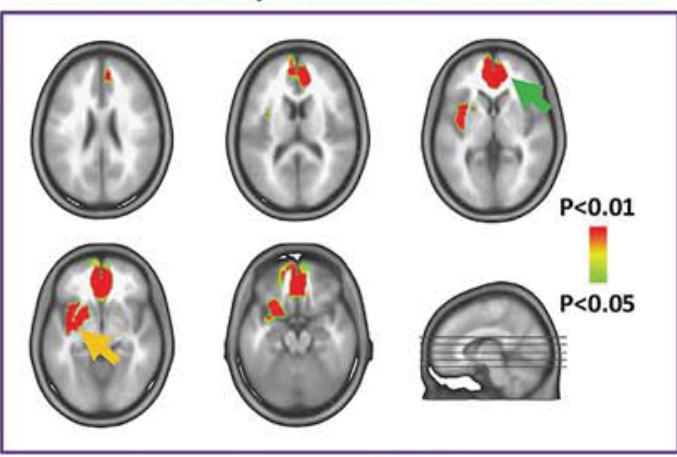

Complex Training Simple Training

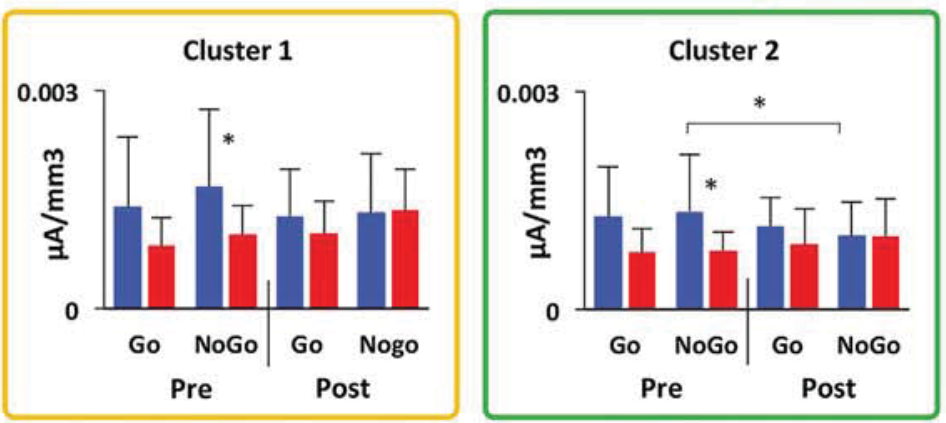

nteraction POI

(200-250ms)

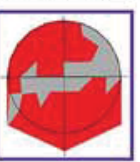

$\mathrm{P}<0.05$
Fig. 4. Electrical neuroimaging analyses: Group = Complex versus Simple; Time $=$ Pre versus Post; Stimulus $=$ Go versus NoGo. A. An exemplar group-averaged ERP waveforms (Fz) is displayed for the two groups and two conditions for each stimulus separately. B. Results of the ERP Group $x$ Time $\times$ Stimulus interaction on the ERP waveforms. The percentage of electrodes showing a significant interaction $(p<.05)$ is displayed for each time point of the epoch. The period of interest (POI) with an interaction for $>10 \%$ during $>22 \mathrm{~ms}$ of the electrodes is highlighted in red. The electrodes showing the interaction over the POI are represented in red on a flattened EEG cap, nasion upward. C. The results of the statistical analyses of the sources estimations averaged over the POI and following the same ANOVA design as for the analyses in the sensor space are displayed on a template brain. Bar graphs represent the averaged ( $+\mathrm{SD}$ ) electrical activity of each cluster (cluster 1: left insula and left inferior frontal gyrus 1 in orange; cluster 2: superior frontal gyrus, medial frontal gyrus and anterior cingulate in green) for each condition.

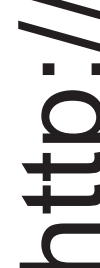


Together with previous evidence for very limited (if any) transfer of EC training (Berkman et al., 2014; Enge et al., 2014; Thorell et al., 2009) our result supports 'chunking' or 'template' theories of learning (Gobet and Simon, 1996; Simon and Chase, 1973) wherein functionally parcellated neural ensembles support specific tasks even though they may overlap spatially on the cortex (Neumann et al., 2016). Accordingly, and compatible with our functional results, training with a specific task would modify the 'template' involved in the task without affecting global, domain-general networks dynamics (Barbey, 2018). Our observed lack of generalization is also in line with our interpretation of the behavioral results as reflecting a rapid automatization of performance during the Complex training task. Task automatization is indeed characterized by a switch from controlled top-down to bottom-up response strategies driven by the direct triggering of task-relevant processes by the stimuli (Spierer et al., 2013 for review). The effects of automatization are thus highly specific to the trained tasks and conditions and such training-induced changes typically do not influence domain-general executive processes (Blacker et al., 2017; Gobet and Simon, 1996; Simon and Chase, 1973).

Future studies should examine whether the transfer tasks actually involve a brain network partly overlapping with the network underlying the training tasks, and if the training intervention also modify functional activity during the transfer tasks; such analyses would allow examining whether the absence of transfer in our behavioral results was however associated with different plastic modifications.

\subsection{Transfer effects manifested during the retention session}

With regards to the persistence of our effects, the Simple group remained better than the Control and the Complex groups on the untrained Go/NoGo task five days after the end of the training. This result is in line with previous findings for long-lasting effects of working memory training (after three months in Jaeggi et al., 2011; after two to six months in Pugin et al., 2014) and Go/NoGo training (after one week in Houben et al., 2011). Surprisingly, a new pattern of results emerged at retention for the Simon task. The Group $\times$ Session interaction at the retention session was driven by better performance in the two training groups than in the Control group. In other words, the training regimen led to a delayed transfer effect on automatic stimulus-response associations conflicting between perceptual and motor representation. This delay could be accounted for by the time needed to consolidate motor memory as demonstrated in studies highlighting the valuable role of time (Lugassy et al., 2018) and sleep (King et al., 2017) in memory consolidation.

\section{Conclusion}

Overall, we demonstrated that extensive executive training with a complex task involving multiple control components has effects highly specific to the trained tasks, even in the presence of differential functional effects within domain-general prefrontal brain areas. Our collective results thus corroborate recent meta-analyses, suggesting very limited, if any, transfer effects of 'brain training' interventions (e.g., Sala and Gobet, 2018), and question the utility of such approaches to improve general cognition and daily functioning.

\section{Declaration of interests}

The authors declare no competing interests.

\section{Acknowledgments}

This work was supported by grants from the Swiss National Science Foundation (Grants \#32003B_156854 and \#320030_175469 to LS). We thank David Nicolas, Lionel Constantin and Benjamin Aebischer for their help with the data collection. The Cartool software (https://sites.goog le.com/site/cartoolcommunity/) has been programmed by Denis Brunet, from the Functional Brain Mapping Laboratory, Geneva, Switzerland, and is supported by the Center for Biomedical Imaging (CIBM) of Geneva and Lausanne. The STEN toolbox (http://doi.org/10. 5281/zenodo.1164038) has been programmed by Jean-François Knebel and Michael Notter, from the Laboratory for Investigative Neurophysiology (the LINE), Lausanne, Switzerland, and is supported by the Center for Biomedical Imaging (CIBM) of Geneva and Lausanne and by National Center of Competence in Research project "SYNAPSY - The Synaptic Bases of Mental Disease”; project no. 51AU40_125759.

\section{Appendix A. Supplementary data}

Supplementary data to this article can be found online

\section{References}

Aron, A.R., Robbins, T.W., Poldrack, A.R., 2014. Inhibition and the right inferior frontal cortex: one decade on. Trends Cognit. Sci. 18 (4), 177-185. https://doi.org/10.1016 j.tics.2013.12.003.

Aron, A.R., Fletcher, P.C., Bullmore, T., Sahakian, B.J., Robbins, T.W., 2003. Stop-signal inhibition disrupted by damage to right inferior frontal gyrus in humans. Nat. Neurosci. 6 (2), 115-116. https://doi.org/10.1038/nn1003.

Barbey, A.K., 2018. Network neuroscience theory of human intelligence. Trends Cognit. Sci. 22 (1), 8-20. https://doi.org/10.1016/j.tics.2017.10.001.

Barkley, R.A., 1996. Linkages between attention and executive functions. In: Attention, Memory, and Executive Function, vols. 307-25. Paul H Brookes Publishing, Baltimore, MD, US.

Beauchamp, K.G., Kahn, L.E., Berkman, E.T., 2016. Does inhibitory control training transfer?: behavioral and neural effects on an untrained emotion regulation task. Soc. Cognit. Affect Neurosci. 11 (9), 1374-1382. https://doi.org/10.1093/scan/nsw061.

Beauchamp, M.H., Dagher, A., D Aston, J.A., Doyon, J., 2003. Dynamic functional changes associated with cognitive skill learning of an adapted version of the tower of London task. Neuroimage 20 (3), 1649-1660. https://doi.org/10.1016/j.neu roimage.2003.07.003.

Benikos, N., Johnstone, S.J., Roodenrys, S.J., 2013. Short-term training in the go/nogo task: behavioural and neural changes depend on task demands. International Journal of Psychophysiology, Electrophysiological and Neuroimaging Studies of Cognitive Control: Evidence from Go/NoGo and Other Executive Function Tasks 87 (3), 301-312. https://doi.org/10.1016/j.ijpsycho.2012.12.001.

Berkman, E.T., Kahn, L.E., Merchant, J.S., 2014. Training-induced changes in inhibitory control network activity. J. Neurosci. 34 (1), 149-157. https://doi.org/10.1523/JNE UROSCI.3564-13.2014.

Berron, D., Frühholz, S., Herrmann, M., 2015. Neural control of enhanced filtering demands in a combined flanker and garner conflict task. PLoS One 10 (3) e0120582. https://doi.org/10.1371/journal.pone.0120582.

Blacker, K.J., Negoita, S., Ewen, J.B., Courtney, S.M., 2017. N-back versus complex span working memory training. Journal of Cognitive Enhancement 1 (4), 434-454. htt ps://doi.org/10.1007/s41465-017-0044-1.

du Boisgueheneuc, F., Levy, R., Volle, E., Seassau, M., Hughes, D., Kinkingnehun, S., Samson, Y., Zhang, S., Dubois, B., 2006. Functions of the left superior frontal gyrus in humans: a lesion study. Brain: J. Neurol. 129 (Pt 12), 3315-3328. https://doi.org/1 0.1093/brain/awl244.

Bokura, H., Yamaguchi, S., Kobayashi, S., 2001. Electrophysiological correlates for response inhibition in a go/nogo task. Clin. Neurophysiol.: Official Journal of the International Federation of Clinical Neurophysiology 112 (12), 2224-2232.

Brass, M., Ruge, H., Meiran, N., Rubin, O., Koch, I., Zysset, S., Prinz, W., von Cramon, Y.D., 2003. When the same response has different meanings:: recoding the response meaning in the lateral prefrontal cortex. Neuroimage 20 (2), 1026-1031. https://doi.org/10.1016/S1053-8119(03)00357-4.

Buschkuehl, M., Hernandez-Garcia, L., Jaeggi, S.M., Bernard, J.A., Jonides, J., 2014. Neural effects of short-term training on working memory. Cognit. Affect Behav. Neurosci. 14 (1), 147-160. https://doi.org/10.3758/s13415-013-0244-9.

Chavan, C.F., Mouthon, M., Draganski, B., van der Zwaag, W., Spierer, L., 2015. Differential patterns of functional and structural plasticity within and between inferior frontal gyri support training-induced improvements in inhibitory control proficiency. Hum. Brain Mapp. 36 (7), 2527-2543. https://doi.org/10.1002/h bm. 22789 .

Chavan, C., Mouthon, M., Simonet, M., Hoogewoud, H-M., Draganski, B., van der Zwaag, W., Spierer, L., 2017. Sustained enhancements in inhibitory control depend primarily on the reinforcement of fronto-basal anatomical connectivity. Brain Struct. Funct. 222 (1), 635-643. https://doi.org/10.1007/s00429-015-1156-y.

Chaytor, N., Schmitter-Edgecombe, M., Burr, R., 2006. Improving the ecological validity of executive functioning assessment. Arch. Clin. Neuropsychol.: The Official Journal of the National Academy of Neuropsychologists 21 (3), 217-227. https://doi. org $/ 10.1016 / j$. acn. 2005.12.002.

Colcombe, S.J., Kramer, A.F., Kirk, I., Erickson, Scalf, P., 2005. The implications of cortical recruitment and brain morphology for individual differences in inhibitory function in aging humans. Psychol. Aging 20 (3), 363-375. https://doi.org/10.1037 /0882-7974.20.3.363. 
Dahlin, E., Neely, A.S., Larsson, A., Bäckman, L., Nyberg, L., 2008. Transfer of learning after updating training mediated by the striatum. Science 320 (5882), 1510-1512. https://doi.org/10.1126/science.1155466.

Danielmeier, C., Wessel, J.R., Steinhauser, M., Ullsperger, M., 2009. Modulation of the error-related negativity by response conflict. Psychophysiology 46 (6), 1288-1298. https://doi.org/10.1111/j.1469-8986.2009.00860.x.

De Pretto, Michael, Rochat, Lucien, Spierer, Lucas, 2017. Spatiotemporal brain dynamics supporting the immediate automatization of inhibitory control by implementation intentions. Sci. Rep. 7 (1), 10821. https://doi.org/10.1038/s41598-017-10832-x.

Donkers, Franc C.L., van Boxtel, Geert J.M., 2004. The N2 in go/no-go tasks reflects conflict monitoring not response inhibition. Brain Cogn. 56 (2), 165-176. https:// doi.org/10.1016/j.bandc.2004.04.005.

Enge, S., Alexander, B., Fleischhauer, M., Küttler, L., Kliegel, M., Alexander S., 2014. No evidence for true training and transfer effects after inhibitory control training in young healthy adults. J. Exp. Psychol. Learn. Mem. Cogn. 40 (4), 987-1001. htt ps://doi.org/10.1037/a0036165.

Enriquez-Geppert, S., Konrad, C., Pantev, C, Huster, J.R., 2010. Conflict and inhibition differentially affect the N200/P300 complex in a combined go/nogo and stop-signa task. Neuroimage 51 (2), 877-887. https://doi.org/10.1016/j.neuroimage.2010.02.0 43.

Eriksen, B.A., Eriksen, C.W., 1974. Effects of noise letters upon the identification of a target letter in a nonsearch task. Percept. Psychophys. 16 (1), 143-149. https ://doi.org/10.3758/BF03203267.

Falkenstein, M., Hoormann, J., Hohnsbein, J., 1999. ERP components in go/nogo tasks and their relation to inhibition. Acta Psychol. 101 (2), 267-291. https://doi.org/10.1016/S0001-6918(99)00008-6.

Faul, F., Erdfelder, E., Lang, A-G, Buchner, A., 2007. G*Power 3: a flexible statistical power analysis program for the social, behavioral, and biomedical Sciences. Behav. Res. Methods 39 (2), 175-191.

ong, Manson C-M, Hui, Nga Y., Fung, E.S.W., Chu, P. C.K., Wang, W. S-Y, 2018. Conflict monitoring in multi-sensory flanker tasks: effects of cross-modal distractors on the N2 component. Neurosci. Lett. 670 (March), 31-35. https://doi.org/10.1016/j.neulet.20 18.01.037.

Gajewski, P.D., Falkenstein, M., 2013. Effects of task complexity on ERP components in go/nogo tasks. Int. J. Psychophysiol.: Official Journal of the International Organization of Psychophysiology 87 (3), 273-278. https://doi.org/10.1016/j.i jpsycho.2012.08.007.

Gobet, F., Simon, H.A., 1996. Templates in chess memory: a mechanism for recalling several boards. Cogn. Psychol. 31 (1), 1-40. https://doi.org/10.1006/cogp.1996. 0011.

Grave de Peralta, M.R., Gonzalez Andino, S., Lantz, G., Michel, C.M., Landis, T., 2001. Noninvasive localization of electromagnetic epileptic activity. I. Method descriptions and simulations. Brain Topogr. 14 (2), 131-137.

Grave-de Peralta, R., González-Andino, S., Gómez-González, C.M., 2004. [The biophysical foundations of the localisation of encephalogram generators in the brain. The application of a distribution-type model to the localisation of epileptic foci]. Rev. Neurol. 39 (8), 748-756.

Guerrieri, R., Nederkoorn, C., Jansen, A., 2012. Disinhibition is easier learned than inhibition. The effects of (dis)inhibition training on food intake. Appetite 59 (1), 96-99. https://doi.org/10.1016/j.appet.2012.04.006.

Guthrie, D., Buchwald, J.S., 1991. Significance testing of difference potentials. Psychophysiology 28 (2), 240-244.

Guye, S., von Bastian, C.C., 2017. Working memory training in older adults: bayesian evidence supporting the absence of transfer. Psychol. Aging 32 (8), 732-746. https ://doi.org/10.1037/pag0000206.

Hartmann, L., Sallard, E., Spierer, L., 2015. Enhancing frontal top-down inhibitory control with go/nogo training. Brain Structure \& Function, October. https://doi.org/10.100 7/s00429-015-1131-7.

Heitz, R.P., 2014. The speed-accuracy tradeoff: history, physiology, methodology and behavior. Front. Neurosci 8, 150. https://doi.org/10.3389/fnins.2014.00150.

Hempel, A., Giesel, F.L., Garcia Caraballo, N.M., Amann, M., Meyer, H., Wüstenberg, T., Essig, M., Schröder, J., 2004. Plasticity of cortical activation related to working memory during training. Am. J. Psychiatry 161 (4), 745-747. https://doi.org/10. 1176/appi.ajp.161.4.745.

Hirose, S., Chikazoe, J., Watanabe, T., Jimura, K., Kunimatsu, A., Abe, O., Ohtomo, K., Miyashita, Y., Konishi, S., 2012. Efficiency of Go/No-Go task performance implemented in the left hemisphere. J. Neurosci. 32 (26), 9059-9065. https:// doi.org/10.1523/JNEUROSCI.0540-12.2012.

Houben, K., Nederkoorn, C., Wiers, R.W., Jansen, A., 2011. Resisting temptation: decreasing alcohol-related affect and drinking behavior by training response inhibition. Drug Alcohol Depend. 116 (1-3), 132-136. https://doi.org/10.1016/j.dru galcdep.2010.12.011.

Jaeggi, S.M., Buschkuehl, M., Jonides, J., Shah, P., 2011. Short- and long-term benefits of cognitive training. Proc. Natl. Acad. Sci. Unit. States Am. 108 (25), 10081-10086. https://doi.org/10.1073/pnas.1103228108.

Jimura, K., Cazalis, F., Stover, E.R.S., Poldrack, R.A., 2014. The neural basis of task switching changes with skill acquisition. Front. Hum. Neurosci. 8, 339. https://doi .org/10.3389/fnhum.2014.00339.

Kamijo, K., Takeda, Y., 2010. Regular physical activity improves executive function during task switching in young adults. Int. J. Psychophysiol. 75 (3), 304-311. https://doi.org/10.1016/j.ijpsycho.2010.01.002.

King, B.R., Hoedlmoser, K., Hirschauer, F., Dolfen, N., Albouy, G., 2017. Sleeping on the motor engram: the multifaceted nature of sleep-related motor memory consolidation. Neurosci. Biobehav. Rev. 80 (September), 1-22. https://doi.org/10.1016/j.neubiore v.2017.04.026.
Kok, A, Ramautar, J.R., De Ruiter, M.B., Guido, P., Band, H., Ridderinkhof, R.K, 2004. ERP components associated with successful and unsuccessful stopping in a stop-signal task. Psychophysiology 41 (1), 9-20. https://doi.org/10.1046/j.1469-8986.2003.00 127.x.

Konishi, S., Nakajima, K., Uchida, I., Kameyama, M., Nakahara, K., Sekihara, K. Miyashita, Y., 1998. Transient activation of inferior prefrontal cortex during cognitive set shifting. Nat. Neurosci. 1 (1), 80-84. https://doi.org/10.1038/283.

Kray, J., Fehér, B., 2017. Age differences in the transfer and maintenance of practiceinduced improvements in task switching: the impact of working-memory and inhibition demands. Front. Psychol. 8, 410. https://doi.org/10.3389/fpsyg.2 017.00410 .

Kropotov, J.D., Ponomarev, V.A., 2009. Decomposing N2 NOGO wave of event-related potentials into independent components. Neuroreport 20 (18), 1592. https://doi.org /10.1097/WNR.0b013e3283309cbd.

Lee, M.D., Wagenmakers, E.-J., 2014. Bayesian Modeling for Cognitive Science: A Practical Course. Cambridge University Press.

Langenecker, S.A., Nielson, K.A., 2003. Frontal recruitment during response inhibition in older adults replicated with fMRI. Neuroimage 20 (2), 1384-1392. https://doi.org/10.1016/S1053-8119(03)00372-0.

Larson, M.J., Clayson, P.E., Clawson, A., 2014. Making sense of all the conflict: a theoretical review and critique of conflict-related ERPs. Int. J. Psychophysiol. 93 (3), 283-297. https://doi.org/10.1016/j.ijpsycho.2014.06.007.

Logan, G.D., Van Zandt, T., Verbruggen, F., Wagenmakers, E-J., 2014. On the ability to inhibit thought and action: general and special theories of an act of control. Psychol. Rev. 121 (1), 66-95. https://doi.org/10.1037/a0035230.

Lugassy, D., Herszage, J., Pilo, R., Brosh, T., Censor, N., 2018. Consolidation of complex motor skill learning: evidence for a delayed offline process. Sleep 41 (9). https:// doi.org/10.1093/sleep/zsy123.

Maguire, M.J., Brier, M.R., Moore, P.S., Ferree, T.C., Ray, D., Stewart, M., Hart, J., Kraut, M.A., 2009. "The influence of perceptual and semantic categorization on inhibitory processing as measured by the N2-P3 response. Brain Cogn. 71 (3), 196-203. https://doi.org/10.1016/j.bandc.2009.08.018.

Manuel, A.L., Bernasconi, F., Spierer, L., 2013. "Plastic modifications within inhibitory control networks induced by practicing a stop-signal task: an electrical neuroimaging study." cortex. a Journal Devoted to the Study of the Nervous System and Behavior 49 (4), 1141-1147. https://doi.org/10.1016/j.cortex.2012.12.009.

Manuel, A.L., Grivel, J., Bernasconi, F., Murray, M.M., Spierer, L., 2010. Brain dynamics underlying training-induced improvement in suppressing inappropriate action. J. Neurosci.: The Official Journal of the Society for Neuroscience 30 (41), 13670-13678. https://doi.org/10.1523/JNEUROSCI.2064-10.2010.

Maraver, M.J., BajoT., M., Gomez-Ariza, C.J., 2016. Training on working memory and inhibitory control in young adults. Front. Hum. Neurosci. 10 (November). https://doi org $/ 10.3389 /$ fnhum.2016.00588.

Menon, V., Uddin, L.Q., 2010. Saliency, switching, attention and control: a network model of insula function. Brain Struct. Funct. 214 (5-6), 655-667. https://doi. org/10.1007/s00429-010-0262-0.

Millner, A.J., Jaroszewski, A.C., Chamarthi, H., Pizzagalli, D.A., 2012. Behavioral and electrophysiological correlates of training-induced cognitive control improvements. Neuroimage 63 (2), 742-753. https://doi.org/10.1016/j.neuroimage.2012.07.032.

Miyake, A., Friedman, N.P., Emerson, M.J., Witzki, A.H., Howerter, A., Wager, T.D., 2000 "The unity and diversity of executive functions and their contributions to complex 'frontal lobe' tasks: a latent variable analysis. Cogn. Psychol. 41 (1), 49-100. https://doi.org/10.1006/cogp.1999.0734.

Miyake, A., Friedman, N.P., 2012. The nature and organization of individual differences in executive functions: four general conclusions. Curr. Dir. Psychol. Sci. 21 (1), 8-14. https://doi.org/10.1177/0963721411429458.

Monsell, S., 2003. Task switching. Trends Cognit. Sci. 7 (3), 134-140.

Neumann, N., Lotze, M., Eickhoff, S.B., 2016. Cognitive expertise: an ALE meta-analysis. Hum. Brain Mapp. 37 (1), 262-272. https://doi.org/10.1002/hbm.23028.

Nielson, K.A., Langenecker, S.A., Garavan, H., 2002. Differences in the functional neuroanatomy of inhibitory control across the adult life span. Psychol. Aging 17 (1), $56-71$

Niendam, T.A., Laird, A.R., Ray, K.L., Dean, Y.M., Glahn, D.C., Carter, C.S., 2012. Metaanalytic evidence for a superordinate cognitive control network subserving diverse executive functions. Cognit. Affect Behav. Neurosci. 12 (2), 241-268. https://doi. org /10.3758/s13415-011-0083-5.

Nieuwenhuis, S., Yeung, N., van den Wildenberg, W., Ridderinkhof, K.R., 2003. Electrophysiological correlates of anterior cingulate function in a go/no-go task: effects of response conflict and trial type frequency. Cognit. Affect Behav. Neurosci. 3 (1), 17-26.

Perrin, F., Pernier, J., Bertrand, O., Giard, M.H., Echallier, J.F., 1987. Mapping of scalp potentials by surface spline interpolation. Electroencephalogr. Clin. Neurophysiol. 66 (1), 75-81.

Pugin, F., Metz, A.J., Stauffer, M., Wolf, M., Jenni, O.G., Huber, R., 2014. Working memory training shows immediate and long-term effects on cognitive performance in children. F1000Research 3, 82. https://doi.org/10.12688/f1000research.3665.2.

Roberts, R.E., Anderson, E.J., Husain, M., 2010. Expert cognitive control and individual differences associated with frontal and parietal white matter microstructure. J. Neurosci.: The Official Journal of the Society for Neuroscience 30 (50), 17063-17067. https://doi.org/10.1523/JNEUROSCI.4879-10.2010.

Rubia, K., Russell, T., Overmeyer, S., Brammer, M.J., Bullmore, E.T., Sharma, T., Simmons, A., et al., 2001. Mapping motor inhibition: conjunctive brain activations across different versions of Go/No-Go and stop tasks. Neuroimage 13 (2), 250-261. https://doi.org/10.1006/nimg.2000.0685. 
Schmajuk, M., Liotti, M., Busse, L., Marty, G., Woldorff, 2006. Electrophysiologica activity underlying inhibitory control processes in normal adults. Neuropsychologia 44 (3), 384-395. https://doi.org/10.1016/j.neuropsychologia.2005.06.005.

Sala, G., Gobet, F., 2018. Cognitive Training Does Not Enhance General Cognition.” Trends in Cognitive Sciences, November. https://doi.org/10.1016/j.tics.2018.10.004.

Sallard, E., Hartmann, L., Ptak, R., Spierer, L., 2018. Spatiotemporal brain dynamics underlying attentional bias modifications. Int. J. Psychophysiol.: Official Journal of the International Organization of Psychophysiology 130 (August), 29-39. https://doi .org/10.1016/j.ijpsycho.2018.06.001.

Salthouse, T.A., 2011. What cognitive abilities are involved in trail-making performance? Intelligence 39 (4), 222-232. https://doi.org/10.1016/j.intell.2011.03.001.

Scharinger, C., Alexander, S., Schubert, T., Gerjets, P., 2015. When flanker meets the Nback: what EEG and pupil dilation data reveal about the interplay between the two central-executive working memory functions inhibition and updating. Psychophysiology 52 (10), 1293-1304. https://doi.org/10.1111/psyp.12500.

Simon, H.A., Chase, W.G., 1973. Skill in chess. Am. Sci. 61, 394-403.

Simon, J.R., 1969. Reactions toward the source of stimulation. J. Exp. Psychol. 81 (1), 174-176. https://doi.org/10.1037/h0027448.

Smith, J.L., Johnstone, S.J., Barry, R.J., 2006. Effects of pre-stimulus processing on subsequent events in a warned go/nogo paradigm: response preparation, execution and inhibition. Int. J. Psychophysiol. 61 (2), 121-133. https://doi.org/10.1016/j.i jpsycho.2005.07.013.

Spierer, L., Chavan, C.F., Manuel, A.L., 2013. Training-induced behavioral and brain plasticity in inhibitory control. Front. Hum. Neurosci. 7, 427. https://doi.org/10.33 89/fnhum.2013.00427.

Stevens, T., Brevers, D., Chambers, C.D., Lavric, A., Ian, P., McLaren, L., Mertens, M., Noël, X., Verbruggen, F., 2015. How does response inhibition influence decision making when gambling? J. Exp. Psychol. Appl. 21 (1), 15-36. https://doi.org// 10.1037/xap0000039.

Swick, D., Ashley, V., Turken, U., 2008. Left inferior frontal gyrus is critical for response inhibition. BMC Neurosci. 9 (October), 102. https://doi.org/10.1186/1471-2202-9-102.

Talanow, T., Ulrich, E., 2018. Effects of task repetition but No transfer of inhibitory control training in healthy adults. Acta Psychol. 187 (June), 37-53. https://doi.org /10.1016/j.actpsy.2018.04.016.

Thorell, L.B., Lindqvist, S., Bergman, S.N., Bohlin, G., Klingberg, T., 2009. Training and transfer effects of executive functions in preschool children. Dev. Sci. 12 (1), 106-113. https://doi.org/10.1111/j.1467-7687.2008.00745.x.

Verbruggen, F., Adams, R., Christopher, D., Chambers, 2012. Proactive motor contro reduces monetary risk taking in gambling. Psychol. Sci. 23 (7), 805-815. https://do .org/10.1177/0956797611434538.

Verbruggen, F., Logan, G.D., 2015. Evidence for capacity sharing when stopping. Cognition 142 (September), 81-95. https://doi.org/10.1016/j.cognition.2015.05.014.

Vuillier, L., Bryce, D., Szücs, D., Whitebread, D., 2016. The maturation of interference suppression and response inhibition: ERP analysis of a cued go/nogo task. PLoS One 11 (11). https://doi.org/10.1371/journal.pone.0165697.

Wade, A., 2005. 1. A Handbook of Statistical Analyses Using SPSS. Sabine Landau and Brian S. Everitt, 2004. No. of Pages: Xii + 354. Price: \$44.95, £ 24, vol. 99. Chapman \& Hall/CRC, Boca Raton, pp. 3236-3237. ISBN: 1-58488-369-3.” Statistics in Medicine 24. https://doi.org/10.1002/sim.2134, 20.

Yeung, N., Cohen, J.D., 2006. The impact of cognitive deficits on conflict monitoring. Predictable dissociations between the error-related negativity and N2. Psychol. Sci. 17 (2), 164-171. https://doi.org/10.1111/j.1467-9280.2006.01680.x. 